\title{
Estimates the Emission of Passenger Cars Based on the First Developed Driving Cycle in Nakhon Ratchasima Municipality, Thailand
}

\author{
Noppatsorn Muangnak ${ }^{1}$, and Nares Chuersuwan ${ }^{2}$ \\ ${ }^{1}$ Graduate Program in Environmental Pollution and Safety, Suranaree University of Technology, Nakhon Ratchasima, Thailand \\ ${ }^{2}$ School of Environmental Health, Suranaree University of Technology, Nakhon Ratchasima, Thailand
}

\begin{abstract}
This study aims to estimate emissions of passenger cars traveled on the highways in Nakhon Ratchasima Municipality (NRM) based on recently developed driving cycles. A mobile phone application (SafeMate) was used to record speed-time of passenger car on the highways both weekday and weekend. The results showed that the driving cycles of the passenger cars on highway 224 and 304 were quite different. More traffic congestion on highway 224 impacted the average speeds, ranging from 10 to $34 \mathrm{~km} / \mathrm{h}$ with longer idling time. The average speeds on highway 304 ranged from 49 to $69 \mathrm{~km} / \mathrm{h}$ with more cruise time. The combined driving cycles on both highways showed the average speeds of $20-40 \mathrm{~km} / \mathrm{h}$ depending upon the time of days. The traffic density on weekday was higher than the weekend. Peak-hour weekday showed lower traffic flow than off-peak hour which was the opposite of the weekend. Based on the derived driving cycles, the passenger car traveled on the highways in NRM emitted CO, NOx and HC approximately 90.7-129.8, 25.5-34.5 and 6.9-11.7 tons/year, respectively. The passenger cars were estimated to emit about 13,927.7-20,419.3 tons/year of carbon dioxide on the highways. The highway 2 accounted more of the emissions due to the traffic volume and coverage distance in NRM.
\end{abstract}

\section{Introduction}

Road transport is a major source of air pollution in Thailand. A number of vehicles has been increased on roadway and caused traffic congestion in several areas, especially in large cities, such as Bangkok, Chiang Mai, Nakhon Ratchasima. Traffic density correlates with high levels of vehicular exhaust emission $[1,2]$ and has potential to cause health effects in urban residents.

Estimating exhaust emissions are conveniently used emission factors and economically attractive. However, the emission inventory requires decent inputs, such as, emission factor of vehicles (EFs), travel activity, etc. Emissions from vehicle depend on several factors, including driving cycle, fuel type, emission control technology, vehicle weight, engine capacity, environment conditions road gradient and the level of vehicle maintenance [3]. Driving cycles have been developed to represent conditions on roads and used in the emission estimates for specific city. The emissions from vehicles are also related to the driving mode: idle, steady-state cruise, acceleration and deceleration.

Driving cycles provide the variations of the vehicle speed with time for a certain period of travel for a specific route. Vehicle emission factors are commonly derived from chassis dynamometer tests programmed with standard driving cycle, such as U.S. Federal Test Procedure (FTP75), Economic Commission for Europe (ECE) and Japanese 10 mode cycle [4]. In turn, the driving cycles used in the U.S. and Europe are not represented the traffic conditions in other regions. Many driving cycles developed elsewhere under specific driving characteristic are clearly differ from one area to another, even within the same city [5] such as Thailand [6] Turkey [7] and China [8]. Consequently, researchers should set priority to specific of driving characteristics in each area to achieve a reliable estimate of the emissions.

This study aims to estimate the emissions of passenger cars traveled on the highways in Nakhon Ratchasima Municipality (NRM) based on recently developed driving cycles with the help of a mobile phone application to record speed-time of the passenger cars.

\section{Methodology}

\subsection{Route selection}

Nakhon Ratchasima Municipality (NRM) is the fifth largest municipality in Thailand that experienced increasing volume of vehicle and traffic congestion due to the subsidy of the First Car Program by the previous government and economic improvement. Four highways, highway number 2, 205, 224, and 304, pass through the municipality. The road sections of those highways were selected to develop the driving cycles of route between Rajamangala University of Technology Isan (RMUTI) to 
Save One Market, approximately 10.17 kilometers trip (Figure 1).

\subsection{Speed data collection}

Since the passenger car shared the largest portion on the highways in NRM, the driving cycle of the passenger car was our focus. In-vehicle method was used to collect speed-time data with the assistant of the mobile application, SafeMate. Data were collected from Monday to Sunday during the morning peak hour (7.00 a.m. -9.00 a.m.), off-peak hour (9.00 a.m. - 3.00 p.m.), and the evening peak hour (3.00 p.m. - 7.00 p.m.). The speedtime data were collected for both inbound and outbound directions.

\subsection{Speed-time analysis and driving cycle development}

The graph data of the speed-time were analyzed by transforming to micro trips for every 7.3 seconds. The speed-time data were separated into weekday and weekend according to peak hour and off-peak hour. Descriptive statistics were used to estimate mean, difference mean, and standard deviation. Difference mean is an accepted mean different at less than $10 \%$. The data were tested for the differences in the dataset using inferential statistic (T-test, Anova test, Mann-Whitney Utest or Kruskal-Wallis). The derived speed data were selected to represent the real driving characteristics of the route. Then, the speed-time data were used to develop driving cycles of the trip.

The micro trips of each highway section were used to construct the driving cycles of the route. Driving characteristic were described by the parameters including average speed $\left(\mathrm{V}_{\mathrm{avg}}\right)$, average running speed $\left(\mathrm{V}_{\mathrm{avg} 1}\right)$, average acceleration of all acceleration phase (Acc), average deceleration of all deceleration phases (Dec), idling mode $\left(\mathrm{T}_{\mathrm{idle}}\right)$, acceleration mode $\left(\mathrm{T}_{\mathrm{acc}}\right)$, deceleration mode $\left(\mathrm{T}_{\text {dec }}\right)$, and cruising mode $\left(\mathrm{T}_{\text {cruise }}\right)$.

\subsection{Estimating passenger car emissions on the highways}

Mobile source emission factors in Thailand has developed on a standard chassis dynamometer, which the exhaust from the vehicles were measured under different situation such as fuel type, emission control technology and driving speed. The air pollutants and greenhouse gas of passenger car were measured including hydrocarbon $(\mathrm{HC})$, carbon monoxide $(\mathrm{CO})$, oxide of nitrogen $\left(\mathrm{NO}_{\mathrm{x}}\right)$ and carbon dioxide $\left(\mathrm{CO}_{2}\right)$ and classified according to speed used in the test [9]. Data from the dynamometer tests were extracted and used to calculate passenger car emissions under the developed driving cycles in NRM. Traffic volume was counted and estimated on all highways according to the Department of Highway, Thailand. The vehicle emission rate was obtained by multiplying vehicle activity with the derived EFs of the passenger car (Eq. 1).

$$
E_{i}=E F_{i} \times D \times N
$$

Where $E F_{i}(\mathrm{~g} / \mathrm{km})$ was an emission factor of $i$ pollutant from vehicle, $D(\mathrm{~km})$ was the travel distance and $N$ (vehicles/day) was average daily traffic. The calculations of exhaust emission under specific driving cycle were estimated using (Eq. 2).

$$
E_{i}=\sum_{i=1}^{a} \sum_{j=1}^{b}\left[E F_{i j} \times T \times n_{j} \times j\right] \times N
$$

Where $E F_{i j}(\mathrm{~g} / \mathrm{km})$ was an emission factor of $i$ pollutant at $j$ travel speed range, $n_{j}$ was the number of micro-trip at $j$ speed range of vehicle on driving cycle, $T=7.31$ (s) was the time scale of micro-trip, $j(\mathrm{~km} / \mathrm{h})$ was a travel speed range of vehicle (including 0-10, 11-20, 21-30, 31-40, 41-50, 51-60, 61-70, 71-80, 81-90 km/h).

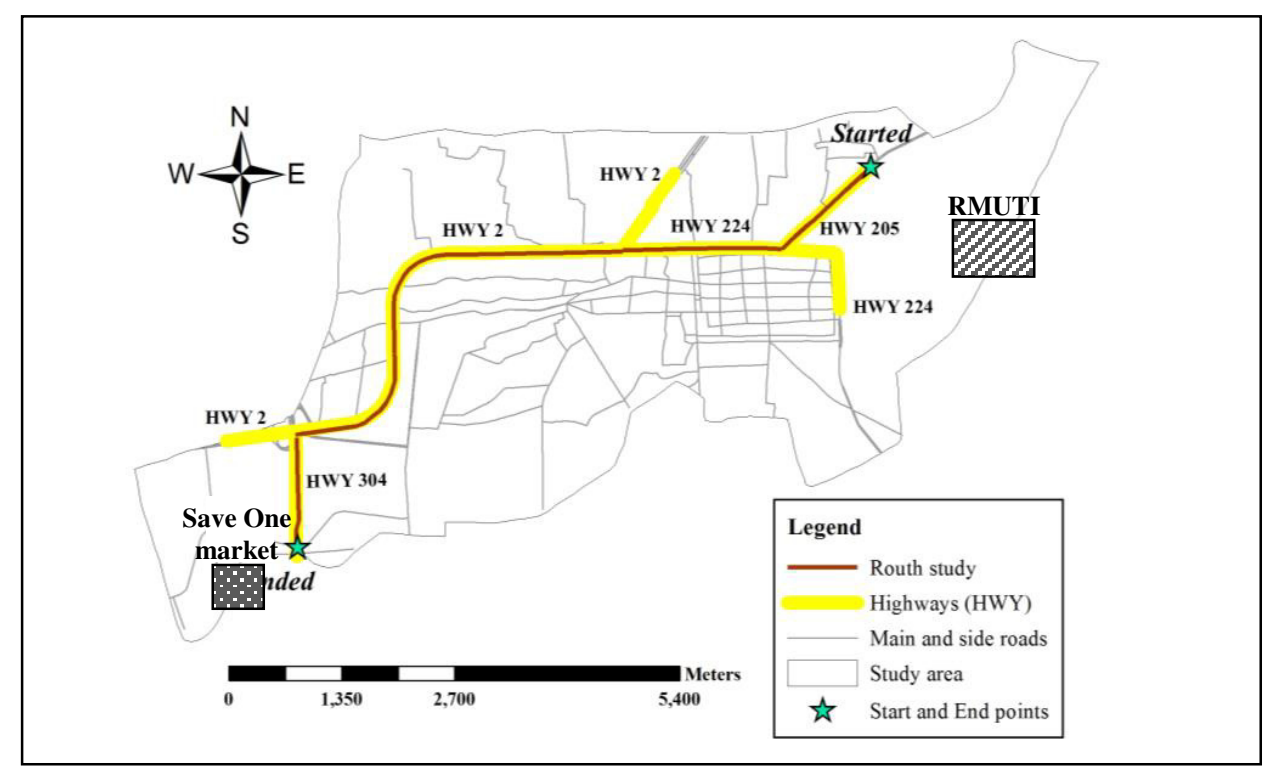

Figure 1. The study area in Nakhon Ratchasima Municipality (NRM) and selected highway route 


\section{Results and discussion}

\subsection{Deriving the highway driving cycles}

Collected speed-time data showed less than 10 percent differences $(p<0.05)$ in the dataset. The driving parameters of all sections of the highways are presented in Table 1. The results showed that the driving cycles on highway 224 and highway 304 differed from the rest, caused by congestion on highways. The average speed of highway 224 was ranged from 10 to $34 \mathrm{~km} / \mathrm{h}$ with longer idling time. The evening peak hour on weekday experienced the congestion. With the average speed of 10 $\mathrm{km} / \mathrm{h}$, the proportion of idle time and cruise were approximately $50 \%$ and $9 \%$, respectively.

Highway 304 experienced less traffic congestion with the average speed ranging from 49 to $69 \mathrm{~km} / \mathrm{h}$ and relatively smooth traffic flow indicating by no idling time and high cruise time. The driving cycle in the morning during the weekend was rather smooth with $50 \%$ of cruise time

The driving cycles on highway 2 and highway 205 were quite fluctuated which the average speed ranged from 32 to 54 and 22 to $42 \mathrm{~km} / \mathrm{h}$, respectively. Weekday had high traffic congestion on both highways. During peak hour, the driving cycles showed high traffic intensity indicated by low speed and fluctuating traffic flow.
The micro trips were used to construct the driving cycles on the highways in NRM for the passenger car travelling about $10.17 \mathrm{~km}$ from the northeast to the southwest locations (Figure 2). With the driving cycles, the driving parameters were derived (Table 2). The results showed that the average speed on weekday and weekend were approximately 23.6 and $34.7 \mathrm{~km} / \mathrm{h}$, respectively. The weekday had more fluctuation than the weekend, indicated by the average idle mode on weekday with the highest proportion of $39 \%$, while the average cruise mode was only $9.7 \%$. Traffic intensity was high on weekday during peak hour while the weekend occurred during off-peak hour. Morning peak and evening peak on weekday showed serious traffic congestion, with the average speed of 22.1 and $20.3 \mathrm{~km} / \mathrm{h}$, respectively. The traffic flow, however, was smooth on morning peak during the weekend with twice the average speed typically found weekday peak hour. The morning peak hour during the weekend had the lowest proportion of idling, about $11.6 \%$. The driving characteristics varied during the day and different times of day and daily. The important factors affected the driving variations in NRM included road characteristics, driving behaviour, and traffic volume, etc. Several studies used speed-time data in morning peak to represent the driving cycles [6], [10], and [11]. In NRM, however, the traffic volume was high during the evening peak hour.

Table 1. The driving parameters on highways in NRM

\begin{tabular}{|c|c|c|c|c|c|c|c|c|c|c|c|c|}
\hline Road sections & $\begin{array}{c}\text { Days } \\
\text { of week }\end{array}$ & Times of day & $\begin{array}{l}V_{\text {avg }} \\
(\mathrm{km} / \mathrm{h})\end{array}$ & $\begin{array}{l}\mathrm{V}_{\text {avgl }} \\
(\mathrm{km} / \mathrm{h})\end{array}$ & $\begin{array}{l}\text { Acc } \\
\left(\mathrm{m} / \mathrm{s}^{2}\right)\end{array}$ & $\begin{array}{l}\text { Dec } \\
\left(\mathrm{m} / \mathrm{s}^{2}\right)\end{array}$ & $\begin{array}{l}\mathrm{T}_{\text {idle }} \\
(\%)\end{array}$ & $\begin{array}{l}\mathrm{T}_{\mathrm{acc}} \\
(\%)\end{array}$ & $\begin{array}{l}\mathrm{T}_{\mathrm{dec}} \\
(\%)\end{array}$ & $\begin{array}{l}\mathrm{T}_{\text {cruise }} \\
(\%)\end{array}$ & $\begin{array}{l}\text { Time } \\
\text { (s) }\end{array}$ & $\begin{array}{c}\text { Length } \\
(\mathrm{km})\end{array}$ \\
\hline \multirow{8}{*}{ Highways 224} & \multirow{4}{*}{ Weekdays } & Morning peak & 11.7 & 24.2 & 0.1 & -0.3 & 49.3 & 17.4 & 21.0 & 12.3 & 1009 & \multirow{8}{*}{3.20} \\
\hline & & off peak & 20.4 & 35.2 & 0.2 & -0.6 & 36.8 & 33.8 & 25.0 & 4.4 & 497 & \\
\hline & & Evening peak & 10.0 & 13.2 & 0.1 & -0.4 & 49.3 & 20.8 & 19.4 & 10.4 & 1053 & \\
\hline & & Average & 14.0 & 24.2 & 0.1 & -0.5 & 45.1 & 24.0 & 21.8 & 9.0 & 853 & \\
\hline & \multirow{4}{*}{ Weekend } & Morning peak & 28.7 & 35.9 & 0.3 & -0.5 & 15.3 & 39.0 & 33.9 & 11.9 & 431 & \\
\hline & & off peak & 34.2 & 38.7 & 0.3 & -0.5 & 11.9 & 47.5 & 37.3 & 3.4 & 431 & \\
\hline & & Evening peak & 19.0 & 40.5 & 0.1 & -0.6 & 50.0 & 23.1 & 17.9 & 9.0 & 570 & \\
\hline & & Average & 27.3 & 38.4 & 0.2 & -0.5 & 25.7 & 36.5 & 29.7 & 8.1 & 477 & \\
\hline \multirow{8}{*}{ Highways 2} & \multirow{4}{*}{ Weekdays } & Morning peak & 44.0 & 58.3 & 0.2 & -0.4 & 22.5 & 33.7 & 31.5 & 12.4 & 651 & \multirow{8}{*}{7.66} \\
\hline & & off peak & 39.6 & 50.9 & 0.1 & -0.3 & 21.5 & 33.6 & 25.2 & 19.6 & 782 & \\
\hline & & Evening peak & 28.9 & 40.1 & 0.2 & -0.3 & 25.8 & 31.5 & 30.6 & 12.1 & 906 & \\
\hline & & Average & 37.5 & 49.8 & 0.2 & -0.3 & 23.3 & 32.9 & 29.1 & 14.7 & 780 & \\
\hline & \multirow{4}{*}{ Weekend } & Morning peak & 53.5 & 59.4 & 0.2 & -0.4 & 7.1 & 32.9 & 32.9 & 27.1 & 512 & \\
\hline & & off peak & 31.7 & 45.6 & 0.2 & -0.4 & 28.2 & 32.5 & 29.1 & 10.3 & 855 & \\
\hline & & Evening peak & 46.4 & 54.5 & 0.3 & -0.5 & 11.3 & 43.8 & 31.3 & 13.8 & 585 & \\
\hline & & Average & 43.9 & 53.2 & 0.2 & -0.5 & 15.5 & 36.4 & 31.1 & 17.0 & 651 & \\
\hline \multirow{8}{*}{ Highways 205} & \multirow{4}{*}{ Weekdays } & Morning peak & 22.3 & 27.6 & 0.2 & -0.4 & 16.7 & 43.3 & 30.0 & 10.0 & 219 & \multirow{8}{*}{1.45} \\
\hline & & off peak & 29.8 & 42.9 & 0.3 & -0.6 & 27.3 & 36.4 & 31.8 & 4.5 & 181 & \\
\hline & & Evening peak & 30.2 & 30.2 & 0.2 & -0.3 & 0.0 & 50.0 & 40.9 & 9.1 & 181 & \\
\hline & & Average & 27.4 & 33.6 & 0.2 & -0.5 & 14.6 & 43.2 & 34.2 & 7.9 & 194 & \\
\hline & \multirow{4}{*}{ Weekend } & Morning peak & 26.5 & 37.1 & 0.3 & -0.7 & 18.5 & 44.4 & 33.3 & 3.7 & 197 & \\
\hline & & off peak & 42.3 & 42.3 & 0.2 & -0.5 & 0.0 & 56.3 & 31.3 & 12.5 & 117 & \\
\hline & & Evening peak & 32.7 & 37.9 & 0.2 & -0.5 & 9.5 & 47.6 & 28.6 & 14.3 & 154 & \\
\hline & & Average & 33.8 & 39.1 & 0.2 & -0.6 & 9.3 & 49.4 & 31.1 & 10.2 & 156 & \\
\hline \multirow{8}{*}{ Highways 304} & \multirow{4}{*}{ Weekdays } & Morning peak & 48.8 & 48.8 & 0.1 & -0.3 & 0.0 & 40.0 & 40.0 & 20.0 & 110 & \multirow{8}{*}{1.63} \\
\hline & & off peak & 54.0 & 54.0 & 0.3 & -0.2 & 0.0 & 53.8 & 38.5 & 7.7 & 95 & \\
\hline & & Evening peak & 53.9 & 53.9 & 0.2 & -0.3 & 0.0 & 53.3 & 40.0 & 6.7 & 110 & \\
\hline & & Average & 52.2 & 52.2 & 0.2 & -0.3 & 0.0 & 49.1 & 39.5 & 11.5 & 105 & \\
\hline & \multirow{4}{*}{ Weekend } & Morning peak & 68.7 & 68.7 & 0.0 & -0.2 & 0.0 & 0.0 & 50.0 & 50.0 & 73 & \\
\hline & & off peak & 58.4 & 58.4 & 0.1 & -0.2 & 0.0 & 33.3 & 40.0 & 26.7 & 110 & \\
\hline & & Evening peak & 62.1 & 66.8 & 0.1 & -0.6 & 0.0 & 30.8 & 38.5 & 30.8 & 95 & \\
\hline & & Average & 63.1 & 64.7 & 0.1 & -0.3 & 0.0 & 21.4 & 42.8 & 35.8 & 93 & \\
\hline
\end{tabular}

Note: Acc $*=$ Acceleration; Dec $* *=$ Deceleration 
Table 2. The driving parameters of passenger car on highway route in NRM

\begin{tabular}{|c|c|c|c|c|c|c|c|c|c|c|c|c|}
\hline Driving cycle & $\begin{array}{c}\text { Days of } \\
\text { week }\end{array}$ & Times of days & $\begin{array}{l}\mathrm{V}_{\text {avg }} \\
(\mathrm{km} / \mathrm{h})\end{array}$ & $\begin{array}{l}\mathrm{V}_{\text {avg1 }} \\
(\mathrm{km} / \mathrm{h})\end{array}$ & $\begin{array}{l}\text { Acc } \\
\left(\mathrm{m} / \mathrm{s}^{2}\right)\end{array}$ & $\begin{array}{l}\text { Dec } \\
\left(\mathrm{m} / \mathrm{s}^{2}\right)\end{array}$ & $\begin{array}{l}T_{\text {idle }} \\
(\%)\end{array}$ & $\begin{array}{l}\mathrm{T}_{\mathrm{acc}} \\
(\%)\end{array}$ & $\begin{array}{l}\mathrm{T}_{\mathrm{dec}} \\
(\%)\end{array}$ & $\begin{array}{l}T_{\text {cruise }} \\
(\%)\end{array}$ & $\begin{array}{l}\text { Time } \\
\text { (s) }\end{array}$ & $\begin{array}{c}\text { Length } \\
(\mathrm{km})\end{array}$ \\
\hline \multirow{8}{*}{$\begin{array}{l}\text { NRMDC } \\
\text { (RMUTI to } \\
\text { Save one market) }\end{array}$} & \multirow{4}{*}{ Weekdays } & Morning peak & 22.1 & 44.2 & 0.1 & -0.4 & 46.5 & 24.3 & 21.6 & 7.6 & 1352 & \multirow{8}{*}{10.3} \\
\hline & & Off peak & 28.4 & 48.0 & 0.1 & -0.5 & 37.0 & 29.5 & 23.3 & 10.3 & 1067 & \\
\hline & & Evening peak & 20.3 & 33.0 & 0.1 & -0.4 & 33.8 & 28.4 & 26.5 & 11.3 & 1491 & \\
\hline & & Average & 23.6 & 41.7 & 0.1 & -0.4 & 39.1 & 27.4 & 23.8 & 9.7 & 1303 & \\
\hline & \multirow{4}{*}{ Weekend } & Morning peak & 39.9 & 49.5 & 0.2 & -0.5 & 11.6 & 37.5 & 33.0 & 17.9 & 826 & \\
\hline & & Off peak & 31.6 & 42.4 & 0.2 & -0.5 & 23.1 & 37.1 & 30.1 & 9.8 & 1052 & \\
\hline & & Evening peak & 32.5 & 51.1 & 0.2 & -0.6 & 31.5 & 32.3 & 24.6 & 11.5 & 957 & \\
\hline & & Average & 34.7 & 47.6 & 0.2 & -0.5 & 22.1 & 35.6 & 29.2 & 13.1 & 945 & \\
\hline
\end{tabular}

Table 3. The comparison of developed driving cycle of passenger car in NRM with international cycles

\begin{tabular}{|c|c|c|c|c|c|c|c|c|c|c|c|c|c|}
\hline $\begin{array}{l}\text { Driving } \\
\text { cycle }\end{array}$ & $\begin{array}{c}\text { Days of } \\
\text { week }\end{array}$ & Times of days & $\begin{array}{l}\mathrm{V}_{\text {avg }} \\
(\mathrm{km} / \mathrm{h})\end{array}$ & $\begin{array}{l}\mathrm{V}_{\text {avgl }} \\
(\mathrm{km} / \mathrm{h})\end{array}$ & $\begin{array}{l}\text { Acc } \\
\left(\mathrm{m} / \mathrm{s}^{2}\right)\end{array}$ & $\begin{array}{l}\text { Dec } \\
\left(\mathrm{m} / \mathrm{s}^{2}\right)\end{array}$ & $\begin{array}{l}\mathrm{T}_{\text {idle }} \\
(\%)\end{array}$ & $\begin{array}{l}\mathrm{T}_{\mathrm{acc}} \\
(\%)\end{array}$ & $\begin{array}{l}\mathrm{T}_{\mathrm{dec}} \\
(\%)\end{array}$ & $\begin{array}{l}\mathrm{T}_{\text {cruise }} \\
(\%)\end{array}$ & $\begin{array}{l}\text { Time } \\
\text { (s) }\end{array}$ & $\begin{array}{l}\text { Length } \\
(\mathrm{km})\end{array}$ & Description \\
\hline \multirow{3}{*}{ NRMDC } & Weekdays & Morning peak & 22.1 & 44.2 & 0.1 & -0.4 & 46.5 & 24.3 & 21.6 & 7.6 & 1352 & \multirow{3}{*}{10.3} & \multirow{3}{*}{ Highway } \\
\hline & Weekend & Morning peak & 39.9 & 49.5 & 0.2 & -0.5 & 11.6 & 37.5 & 33.0 & 17.9 & 826 & & \\
\hline & Week & Morning peak & 31.0 & 46.9 & 0.2 & -0.5 & 29.1 & 30.9 & 27.3 & 12.8 & 1089 & & \\
\hline MIDC & Weekdays & Morning peak & 26.9 & 37.5 & 0.6 & -0.9 & 28.4 & 20.7 & 15.8 & 35.2 & 1744 & 13.0 & Highway [10] \\
\hline HKHDC & Week & Morning peak & 38.3 & 41.8 & 0.4 & -0.4 & 8.4 & 37.5 & 36.2 & 17.2 & 1401 & 14.9 & Highway [11] \\
\hline $\mathrm{BDC}$ & Week & Morning peak & 17.7 & 28.8 & 0.7 & -0.7 & 37.7 & 15.3 & 23.2 & 23.8 & 1160 & 5.7 & $\begin{array}{l}\text { Arterial and } \\
\text { highway [6] }\end{array}$ \\
\hline
\end{tabular}

Note: NRMDC $=$ Nakhon Ratchasima Municipality Driving Cycle, MIDC $=$ Modified Indian Driving Cycle, HKHDC $=$ Hong Kong Highway Driving Cycle and BDC = Bangkok Driving Cycle.
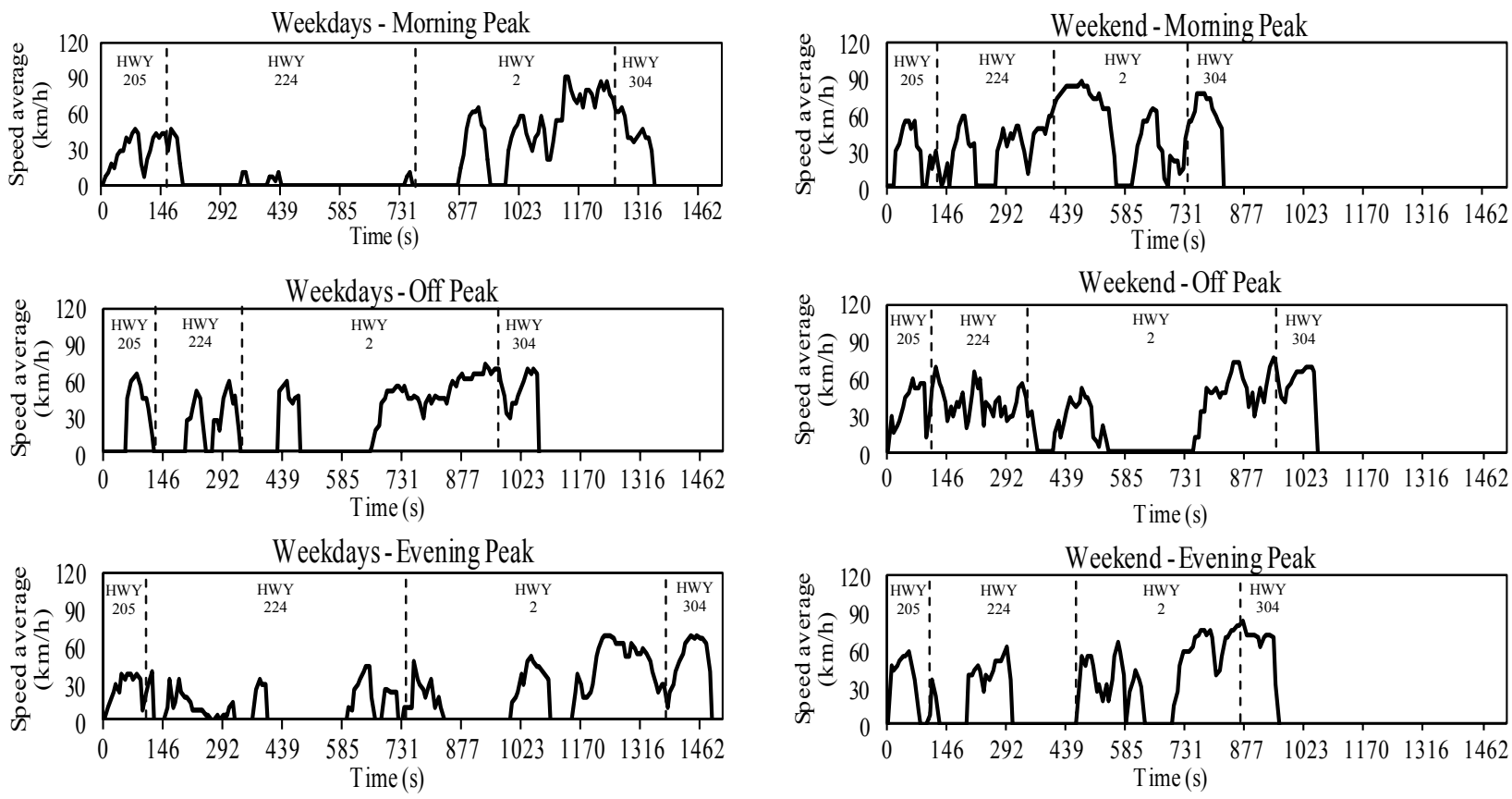

Figure 2. Driving cycles on highway (HWY) route in NRM.

The morning peak was selected as the driving cycles of passenger car in NRM. The comparison with other driving cycles in other countries is in Table 3. The average speed of NRMDC on weekday morning peak was lower than MIDC due to the high traffic congestion in NRM. NRMDC had high portion of idle time, approximately $46.5 \%$. The driving cycle on the morning peak of HKHDC and BDC were obviously differed from NRMDC. The average speed of HKHDC, NRMDC and BDC were about $38.3,31.0$ and $17.7 \mathrm{~km} / \mathrm{h}$, respectively.

HKHDC showed higher fluctuation than other driving cycles. High portion of acceleration time and deceleration was approximately $37.5 \%$ and $36.2 \%$, respectively. Values of the driving parameters between BDC and NRMDC were different. BDC had the lowest average

speed and running speed comparing to others driving cycles. The reason that BDC was developed based on traffic conditions of both highway and arterial road, where the arterial roads in Bangkok had serious traffic congestion [6]. Therefore, it was necessary to develop the specific driving cycles in NRM with more appropriate speed-time data for the estimation of the vehicular emissions.

\subsection{Estimated passenger car emissions on highways in NRM}

Estimation of mobile emission in NRM was obtained from multiplying average annual daily traffic (AADT) with vehicle kilometer travel and the emission factors. 
The estimation of exhaust emissions from passenger car on highways in NRM is shown in Table 4. Based on 2015 data, the main air pollutant was carbon monoxide, about 90.7-129.8 tons annually. As a greenhouse gas, annual $\mathrm{CO}_{2}$ emission was at high as $20,419.3$ tons. Highway 2 accounted a large portion of the emissions due to the

Table 4. Estimated total emissions from passenger cars on the highways in NRM, 2015

\begin{tabular}{|c|c|c|c|c|c|c|c|c|c|c|}
\hline \multirow{3}{*}{ Section road } & \multirow{3}{*}{$\begin{array}{l}\text { Distance } \\
(\mathrm{km})\end{array}$} & \multirow{3}{*}{$\begin{array}{l}\text { AADT } \\
\text { (vehicle/day) }\end{array}$} & \multicolumn{8}{|c|}{ Emissions (tons/year) } \\
\hline & & & \multicolumn{2}{|c|}{$\mathrm{HC}$} & \multicolumn{2}{|c|}{$\mathrm{CO}$} & \multicolumn{2}{|c|}{$\mathrm{NO}_{\mathrm{x}}$} & \multicolumn{2}{|c|}{$\mathrm{CO}_{2}$} \\
\hline & & & Low & High & Low & High & Low & High & Low & High \\
\hline Highway 2 & 7.66 & 30839 & 4.9 & 7.4 & 67.4 & 90.2 & 19.2 & 24.3 & 10242.1 & 13883.8 \\
\hline Highway 205 & 1.46 & 22908 & 0.7 & 1.2 & 9.4 & 13.4 & 2.5 & 3.5 & 1456.1 & 2132.7 \\
\hline Highway 224 & 3.20 & 12285 & 1.1 & 2.8 & 11.4 & 23.2 & 3.1 & 5.9 & 1858.3 & 3964.0 \\
\hline Highway 304 & 1.69 & 5743 & 0.2 & 0.2 & 2.5 & 2.9 & 0.7 & 0.8 & 371.2 & 438.8 \\
\hline \multicolumn{3}{|c|}{ Total emission (tons/year) } & 6.9 & 11.7 & 90.7 & 129.8 & 25.5 & 34.5 & 13927.7 & 20419.3 \\
\hline \multicolumn{3}{|c|}{ Percent emission $(\%)$} & \multicolumn{2}{|c|}{0.03} & \multicolumn{2}{|c|}{0.32} & \multicolumn{2}{|c|}{0.09} & \multicolumn{2}{|c|}{49.57} \\
\hline
\end{tabular}

\section{Conclusions}

Specific driving cycle is important for reasonable estimate of air emissions in area of interest like NRM. The driving cycles can be constructed based on the information of micro trips from speed-time data. Current technology allows a mobile application to assist data gathering of the traffic related data virtually in any city. Along with the traffic volume and appropriate emission factors, vehicle emissions can be routinely estimate. The passenger cars in NRM had different driving patterns depending on time of the day and day of the week. Long idling time of passenger car on highway in NRM was weekday was about $23.6 \mathrm{~km} / \mathrm{h}$, and $34.7 \mathrm{~km} / \mathrm{h}$ during weekend. The weekday had more speed fluctuation than the weekend, indicated by the average idle mode on weekday with the highest proportion of $39 \%$, while the average cruise mode was only $9.7 \%$. In 2015 , annual carbon monoxide was emitted about 91-130 tons, 26-35 tons of $\mathrm{NO}_{\mathrm{x}}$, and 7-12 tons of $\mathrm{HC}$. The future research should further investigate other types of roads and vehicles to quantify the whole fleet and to provide the overall vehicle emission inventory for the comprehensive air quality planning.

\section{Acknowledgement}

The authors would like to thank the Automotive Emission Laboratory of Pollution Control Department, Thailand for supporting the vehicle emission factors in Thailand.

\section{References}

1. S. T. Leong, S. Muttamara and P. Laortanakul, Air Pollution and Traffic Measurements in Bangkok Streets, Asian Journal on Energy and Environment, Vol. 3, pp. 185-213, (2003).

2. S. Pandian, S. Gokhale, A. K. Ghoshal, Evaluating effects of traffic and vehicle characteristics on vehicular emissions near traffic intersections, affected by the traffic activities. The average speed on travel distance and traffic volume. The estimated annual emissions of $\mathrm{CO}, \mathrm{NO}_{\mathrm{x}}$, and $\mathrm{HC}$ from highway 2 were approximately $67.4-90.2,19.2-24.3$ and $4.9-7.4$ tons, respectively, whereas highway 304 had the smallest portion of the emissions from passenger cars.
Transportation Research Part D: Transport and Environment, Vol. 14, pp. 180-196, (2009).

3. A. Faiz, C. S. Weaver and M. P. Walsh, Air pollution from motor vehicles: Standards and technologies for controlling emissions. 1st ed. Washington DC, USA: The World Bank, ch. 1, pp. 1-24, (1996).

4. US. EPA. Vehicle and Fuel Emissions Testing. [Online]. Available: https://www.epa.gov/vehicleand-fuel-emissions -testing/dynamo meter-driveschedules, (January, 2017).

5. H.Y. Tong, W.T. Hung and C.S. Cheung, Development of a driving cycle for Hong Kong, Atmospheric Environment, Vol. 33, pp. 2323-2335, (1999).

6. N. Tamsanya and S. Chungpaibulpatana, Influence of driving cycles on exhaust emissions and fuel consumption of gasoline passenger car in Bangkok, Journal of Environmental Sciences, Vol. 21, pp. 604611, (2009).

7. J. Lin and D. A. Niemeier, Regional driving characteristics, regional driving cycles, Transportation Research Part D: Transport and Environment, Vol. 8, pp. 330-346, (2003).

8. Q. Wang, H. Huo, Kebin He, Z. Yao and Q. Zhang, Characterization of vehicle driving patterns and development of driving cycles in Chinese cities, Transportation Research Part D: Transport and Environment, Vol. 13, pp. 289-297, (2008).

9. I. Pawarmart, T. Petplangsri and N. Pala-en, Update mobile source emission factors in Thailand, presented at 5th International Conference on Sastainable Energy and Environment, Bangkok, Thailand, (2014)

10. P. Adak, R. Sahu and S. P. Elumalai, Development of emission factors for motorcycles and shared autorickshaws using real world driving cycle for a typical Indian city, Science of the Total Environment, vol. 544, pp. 299-308, (2016).

11. W. T. Hung, H. Y. Tong, C. P. Lee, K. Ha and L. Y. Pao, Development of a practical driving cycle construction methodology: A case study in Hong Kong, Transportation Research Part D, vol. 12. pp. 115-128, (2007). 